APO-1 (pg/ml) and sFasL $(\mathrm{ng} / \mathrm{ml})$ were measured by ELISA (Bender MedSystem $\mathrm{GmbH}$, Austria).

Results: Median SLE duration was 5 [1-11] years, SLEDAI 2K-9,5 [4,0-16,0], SLICC-0 [0-1], current prednisone dose-5,0 [0-11,9] mg/day, 44\% of pts received hydroxychloroquine, $17 \%>$ cyclophosphamide, $10 \%>$ azathioprine, $4 \%$ $>$ mycophenolate mofetil, $8 \%$ > biologics. SLEpts had higher level of IL-6 vs control $(2,9[1,5-9,7]$ vs $1,4[0,7-2,1] \mathrm{pg} / \mathrm{ml}, \mathrm{p}<0,01)$ and lower level of TNF- $\alpha(1,9[0,5-$ $3,2]$ vs $4,5[3,5-6,4] \mathrm{pg} / \mathrm{ml}, \mathrm{p}<0,0001)$, lower levels of sFas/APO-1 vs control $(657,5[483,2-791,4]$ vs $1456,9[426,5-2060,8] \mathrm{pg} / \mathrm{ml}, \mathrm{p}>0,05)$ and lower levels of sFasL vs control $(0,01[0,01-0,03]$ vs $0,07[0,05-0,10] \mathrm{ng} / \mathrm{ml}, \mathrm{p}<0,0001)$. In SLE pts serum level IL-6 correlated with IgM $(r=0,69, p<0,01), \mathrm{K}^{+}(\mathrm{r}=0,43, \mathrm{p}<0,01)$, TNF- $\alpha(r=0,50, p<0,001)$, APRIL $(r=0,39, p<0,01)$ and sFas/APO-1 levels $(r=0,29$, $p<0,05)$; TNF- $\alpha$ level correlated with $\operatorname{SLICC}(r=0,32, p<0,05)$, APRIL $(r=0,42$, $p<0,01)$, IL-6 $(r=0,50, \quad p<0,001)$, haemoglobin concentration $(r=0,39, p<0,01)$, sFasL $(r=0,44, p<0,01)$ and total cyclophosphamide dose $(r=0,28, p<0,05)$. We divided SLEpts on two groups: the 1st-pts $(n=31)$ with high activity (SLEDAI $2 \mathrm{~K} \geq 8$ ), the $2 \mathrm{nd}-\mathrm{pts}(\mathrm{n}=21)$ with low (SLEDAI $2 \mathrm{~K}<8)$. The pts in the 1 st group had lower level of TNF- $\alpha$ compared to 2 nd $(1,6[0,3-2,2]$ vs $2,8[1,3-4,5] \mathrm{pg} / \mathrm{ml}$, $\mathrm{p}<0,05$ ), with no difference in IL-6 level.

Conclusions: SLEpts demonstrated higher IL- 6 and lower TNF- $\alpha$ levels as compared to healthy controls. Pts with high activity of SLE had decreased level of TNF- $\alpha$. There is no correlation between disease activity and IL- 6 level, as well as between elevated IL- 6 and acute phase indicators. We suggest an immunoregulatory not proinflammatory role of IL- 6 in SLE and probable protective role of TNF- $\alpha$ in SLE pathogenesis (it's deficiency can lead to the development and high activity of SLE). There was no correlation between IL-6. TNF- $\alpha$ levels and any SLE features. The correlation of IL- 6 with sFas/APO-1 level (apoptosis inhibitor that blocks binding of sFas/APO-1 to sFasL) and TNF- $\alpha$ with sFasL concentration (a marker of apoptosis) suggests their different roles in the mechanisms of apoptosis.

Disclosure of Interest: None declared

DOI: 10.1136/annrheumdis-2018-eular.3220

\section{AB0631 IS HYPERHOMOCYSTEINEMIA (HHC) ADDITIONAL RISK FACTORS OF THROMBOSES IN PATIENTS WITH SYSTEMIC LUPUS ERYTHEMATOSUS AND ANTIPHOSPHOLIPID SYNDROME}

T.M. Reshetnyak ${ }^{1,2}$, N.V. Seredavkina ${ }^{1}$, E.L. Nasonov ${ }^{1}$, L.I. Patrushev ${ }^{3} .{ }^{1}$ Vascular Rheumatology, V.A. Nasonova Reasearch Institute of Rheumatology; ${ }^{2}$ Russian Medical Academy of Postgraduate Education; ${ }^{3}$ Shemyakin-Ovchinnikov Institute of Biorganic Chemistry of RAS, Moscow, Russian Federation

Background: HHC may be additional factor of thrombosis in SLE patients Objectives: To assess the role of $\mathrm{HHC}$ as additional risk factors in development of vascular complications in SLE and antiphospholipid syndrome (APS).

Methods: A total of 125 patients $(24 \mathrm{M}$ and $101 \mathrm{~F}$, mean age $38 \pm 13$ years and the disease duration $14 \pm 11$ years) were divided into three groups: group $1-$ SLE patients $(n=51)$; group $2-$ SLE +APS patients $(n=49)$; group 3 - primary APS patients $(n=25)$. Homocystein $(H C)$ was assayed by high performance liquid chromatography. DNA diagnostics by the method of polymerase chain reaction was used to determine gene mutation C677T methylenetetrahydrofolate (MTHFR) reductase in 93 out of 125 patients.

Results: $\mathrm{HHC}(\mathrm{HC}>15 \mathrm{mcg} / \mathrm{L})$ was diagnosed in 82 of $125(66 \%)$ patients: in $59 \%$ patients of group $1,67 \%$ - of group $2 \%$ and $76 \%$ - of group 3 . There was a relationship between $\mathrm{HHC}$ and digital necrosis (DN): $80 \%$ of patients with DN had $\mathrm{HHC}$ while $\mathrm{HHC}$ was in $57 \%$ patients without $\mathrm{DN}\left(\mathrm{c}^{2}=4.76, \mathrm{p}=0.03\right)$. Elevated level of $\mathrm{HC}$ was registered in 43 of $55(78 \%)$ APS patients with thromboses vs. 9 of 19 (47\%) aPL-positive SLE patients without thromboses $(p=0.03)$. HHC occurred significantly more frequently in patients with arterial thromboses (in all 14 patients) than in patients with venous thromboses - in 16 of $23(69.9 \%)$ pts ( $p=0.03)$ and in the absence of thromboses $(p=0.04)$. HHC was associated with thromboses of cerebral (in 90\%), peripheral arteries (in 84\%) and myocardial infarction (in 79\%) vs. $47 \%$ of patients without thromboses ( $p=0.005 ; p=0.04, p=0.04$ respectively), ( 79 vs. $47 \%$,). Mutation of C677T MTHFR was revealed in $33.3 \%$ of SLE patients, in $57.7 \%$ - of SLE +APS and in $63.2 \%$ - PAPS. Mutation C677T in the gene MTHFR was detected in $57 \%$ of examined patients, $20 \%$ of them had homozygous variant and $80 \%$ are heterozygous. Patients with a homozygous C677T MTHFR gene was observed the tendency to develop arterial thrombosis Conclusions: More than $50 \%$ APS pts had elevated level of $\mathrm{HC}$ as additional thromboses factors. Correlation between $\mathrm{HHC}$ and thromboses, primarily arterial, in APS patients gives grounds for the role of $\mathrm{HHC}$ in development of vascular complications in SLE and APS pts.
Disclosure of Interest: None declared

DOI: 10.1136/annrheumdis-2018-eular.2484

\section{AB0632 ESSDAI DOMAIN EVALUATION OF PRIMARY SJÖGREN'S SYNDROME (PSS) PATIENTS ENROLLED IN TWO INDEPENDENT POC STUDIES INDICATES DIFFERENTIAL UTILITY OF DOMAINS FOR TRIAL INCLUSION AND COMPOSITE ENDPOINTS IN PSS TRIALS}

T. Dörner ${ }^{1}$, B.A. Fisher ${ }^{2}$, X. Ren ${ }^{3}$, P. Faerber ${ }^{3}$, P. Gergely ${ }^{3}$, L. Mooney ${ }^{3}$, Y. Li ${ }^{3}$, S J. Oliver ${ }^{3}$, W. Hueber ${ }^{4}$, A.M. Wright ${ }^{3} .{ }^{1}$ Charité Hospital, Berlin, Germany;

${ }^{2}$ Rheumatology Research Group, University of Birmingham, Birmingham, UK;

${ }^{3}$ Novartis Institutes for BioMedical Research; ${ }^{4}$ Novartis Pharma, Basle, Switzerland

Background: According to international consensus, disease activity in primary Sjögren's syndrome (pSS) patients shall be scored across 12 different domains according to the European Sjögren Syndrome Disease Activity Index (ESSDAI ${ }^{1}$ ). Two separate phase 2 proof-of-concept $(\mathrm{PoC})$ studies using either BAFF receptor inhibitor (VAY736; ianalumab) or CD40 inhibitor (CFZ533) have recently been completed in comparable pSS cohorts with ESSDAI as the primary endpoint.

Objectives: To evaluate contribution of individual domains to composite ESSDAI scores at baseline and after interventional treatment with either VAY736 or CFZ533, or placebo. Aggregate efficacy and safety results were presented at previous meetings. ${ }^{23}$

Methods: Key inclusion criteria for both studies were fulfilling revised European US consensus criteria for pSS, ${ }^{4}$ autoantibody positivity, exclusion of secondary $S S$ and ESSDAI $\geq 6$. Permitted background medications in both trials included stable doses of hydroxychloroquine, methotrexate and prednisone $\leq 10 \mathrm{mg} / \mathrm{d}$ and also azathioprine in the CFZ533 trial. The primary endpoint was change in ESS DAl at week 12. Descriptive and principal component analysis were done with the goal to identify distinct subgroups of patients based on ESSDAI involvement at baseline $(\mathrm{BL})$, and the relative importance of single domain contribution to overall ESSDAI responses were explored.

Results: 27 patients received single i.v. dose VAY736 $10 \mathrm{mg} / \mathrm{kg}(\mathrm{n}=12)$ or $3 \mathrm{mg} /$ $\mathrm{kg}(\mathrm{n}=6)$ or placebo, and 44 patients received multiple doses of CFZ533 $10 \mathrm{mg} / \mathrm{kg}$ i.v. $(n=21)$ or $3 \mathrm{mg} / \mathrm{kg}$ s.c. $(\mathrm{n}=8)$ or placebo. ESSDAI breakdown at BL showed a predominance of the articular, glandular, biological, constitutional and lymphadenopathy domains in both trials. Activity in more than 3 domains was recorded for $12 / 27(44 \%)$ and $12 / 44(27 \%)$ of patients in the VAY736 and CFZ533 studies, respectively. Principal component analysis identified the articular domain as the key component describing the difference between patients in their ESSDAI domains at BL. Two other domains that explained the variability between patients were the biological and glandular domains. Treatment effects in domains with low $\mathrm{BL}$ scores were more difficult to assess using ESSDAI. The majority of ESSDAI domains were not amenable to quantitative analysis, due to absence or low incidence at baseline.

Conclusions: The most frequently observed ESSDAI domain was articular involvement. Our results provide insights into ESSDAI domain frequency and distribution in the randomised controlled trial setting that may have implication for future trial design in pSS.

\section{REFERENCE:}

[1] Seror R, et al. (2016) Ann Rheum Dis 75:382-389.

[2] Dörner Th, et al. (2016) Arthritis Rheumatol 68 Suppl 10;

[3] Fisher B, et al. (2017) Arthritis Rheumatol 69; Suppl 10;

[4] Vitali C, et al. (2002) Ann Rheum Dis 61:554-558.

Disclosure of Interest: T. Dörner Grant/research support from: Novartis, Charite CRO, Consultant for: Novartis, B. Fisher Consultant for: Novartis, Roche, BMS and AstraZeneca/Medlmmune., X. Ren Employee of: Novartis Pharmaceuticals, P. Faerber Employee of: Novartis Pharmaceuticals, P. Gergely Shareholder of: Novartis Pharmaceuticals, Employee of: Novartis Pharmaceuticals, L. Mooney Employee of: Novartis Pharmaceuticals, Y. Li Shareholder of: Novartis Pharmaceuticals, Employee of: Novartis Pharmaceuticals, S. Oliver Shareholder of: Novartis Pharmaceuticals, Employee of: Novartis Pharmaceuticals, W. Hueber Shareholder of: Novartis Pharmaceuticals, Employee of: Novartis Pharmaceuticals, A. Wright Shareholder of: Novartis Pharmaceuticals, Employee of: Novartis Pharmaceuticals

DOI: 10.1136/annrheumdis-2018-eular.4441 